\title{
Da fundamentação jusfilosófica à prática dos direitos humanos: crítica desde os direitos da pessoa idosa
}

From jusphilosophical reasoning to the practice of human rights:

criticism from the rights of the elderly

\section{André Luiz Pereira Spinieli \\ andre.spinieli@unesp.br}

Mestrando em Direito pela Universidade Estadual Paulista - Unesp.

\section{Ana Paula Rodrigues Nalin ap.nalin@unesp.br}

Graduanda em Direito pela Universidade Estadual Paulista - Unesp.

\section{Resumo}

Como os direitos humanos, o conceito de dignidade humana foi forjado segundo as ferramentas da filosofia ocidental, ofertando uma perspectiva de progresso social para grupos considerados vulneráveis e inseridos à margem dos projetos coletivos. A proposta deste artigo é apresentar a fundamentação do ideal clássico de direitos humanos e uma visão crítica sobre essas garantias, tendo como cerne a tutela da pessoa idosa.

Palavras-chave: direitos humanos; pessoa idosa; teoria crítica; dignidade humana; filosofia.

\begin{abstract}
Like human rights, the concept of human dignity was forged according to the tools of Western philosophy, offering a perspective of social progress for groups considered vulnerable and placed on the margins of collective projects. The purpose of this article is to present the rationale for the classic ideal of human rights and a critical view of these guarantees, having as its core the protection of the elderly.
\end{abstract}

Keywords: human rights; elderly; critical theory; human dignity; philosophy 


\section{Introdução}

A dissociação entre teoria e prática dos direitos humanos provoca violações e ausências de materializações que repercutem diretamente na vivência das populações vulneráveis, cujo recorte se dá em relação às pessoas idosas. A formalização legal dos direitos humanos é suficiente para a salvaguarda dessa população, ainda que sejam construídos a partir da premissa da dignidade humana? Para tal análise, metodologicamente, este artigo emprega a abordagem dedutivo-bibliográfica e se divide em três momentos: primeiramente, há fundamentação dos conceitos de dignidade e direitos humanos, por meio de uma análise jusfilosófica; posteriormente, uma compreensão mais crítica e não estática desses conceitos; e, por fim, uma abordagem voltada ao envelhecimento saudável e velhice como categorias inerentes aos direitos humanos.

\section{A fundamentação jusfilosófica da dignidade e dos direitos humanos}

O conceito de dignidade humana constitui um aporte teórico-prático fundamental para a realização material dos direitos humanos na contemporaneidade (Sarmento, 2016, p.69-70), servindo não apenas como um guia para a produção de leis, declarações e tratados internacionais, sobretudo aqueles que estão vinculados à ideia de promoção da cidadania de grupos considerados vulneráveis, mas também como mecanismo de proteção integral à pessoa humana, sem que, para isso, seja necessário recortar direitos ou aspectos de sua personalidade (Sarmento, 2016, p.89-90). Se a vulnerabilidade representa uma determinação de fatores múltiplos, que contribuem diretamente para a inserção de sujeitos de direito em condições de inacessibilidade aos seus direitos fundamentais, a bens e serviços públicos (Carmo; Guizardi, 2018, p.2), atingindo diferentes grupos que permanecem em posições inferiormente hierárquicas na sociedade, a dignidade representa o instrumento útil à consolidação de um mínimo existencial (Sarmento, 2016, p.195).

Em realidade, para uma compreensão acerca das bases e origens dos direitos humanos e, principalmente, do conceito de dignidade humana, tornou-se indispensável associar a construção dessas garantias à perspectiva jusfilosófica. Ainda que toda a história da filosofia ocidental seja útil à compreensão do itinerário traçado pelos direitos humanos, a qual tem como ponto de partida as especulações da antiguidade clássica socrática e seu (parcial) fechamento na contemporaneidade, com visões críticas sobre o conceito de alteridade e do reconhecimento 
do outro, há nomes centrais que não podem ser esquecidos no âmbito da conceituação de dignidade humana - e dos direitos humanos, por consequência: Platão, Tomás de Aquino, Pico della Mirandola e Immanuel Kant. O pensamento desses autores foi central para que a comunidade ocidental gestasse e concebesse uma ideia de direitos humanos que tivesse como características o universalismo (Sarmento, 2016, p.17; Trindade, 2003, p.36).

Platão (427-347 a.C.) é filho de um período histórico da filosofia ocidental em que as sociedades clássicas, gregas e romanas, já se organizavam em comunidade segundo um princípio político. Para os gregos, a política representava a boa condução da polis em prol das necessidades e dos valores (ou não valores) daqueles que eram considerados cidadãos ou não (Jaeger, 1995, p.7). Atento às necessidades políticas da sociedade grega e com uma proposta filosófica que tinha como cerne a perspectiva gnosiológica e epistemológica - de estudo sobre as bases do conhecimento verdadeiro -, Platão se tornou um defensor nato e um praticante, na Academia, da ideia educacional de Paideia, um modelo de cultura na qual o aluno receberia uma formação ampla e integral, que atingia disciplinas teóricas e práticas (Jaeger, 1995, p.106), tornando-se apto a conduzir o governo de acordo com a perspectiva platônica, ou seja, como um rei-filósofo. Como reflexo, os conceitos de justiça e dignidade humana estavam intimamente relacionados ao ideal da cultura grega desenvolvida no modelo da Paideia. No pensamento de Platão, o homem justo e que faz uso da dignidade humana somente poderia ser aquele que compreendesse o sentido da educação como uma medicina da alma (Jaeger, 1995, p.812).

Historicamente mais tarde, o período medieval representou o instante de divulgação da mensagem bíblica e o assentamento da Igreja Católica como instituição política, eclesiástica e formativa fundamental para tal momento. Nesse instante, as contribuições filosóficas estiveram umbilicalmente vinculadas ao princípio teológico, uma vez que tinham como finalidade explicar e fundamentar, por meio do conhecimento e das bases filosóficas construídas pelos gregos e romanos, as verdades da fé. No âmbito do direito, dos direitos humanos e da concepção de dignidade humana, destaca-se o pensamento de Tomás de Aquino (1225-1274), que sintetizou a filosofia medieval na Summa Theologica e realizou uma adequação das contribuições aristotélicas às verdades teológicas, além de servir de crítica à descaracterização da filosofia de Aristóteles que se realizava por meio dos pensadores árabes (Salles, 2015). Nesse sentido, para Tomás de Aquino, desde os homens até as criaturas celestes, como os anjos, tudo aquilo que pode ser considerado bom é necessariamente dotado de dignidade, tratando-se de uma característica que é inerente ao homem (Salles, 2015). 
SPINIELI, André Luiz Pereira; NALIN, Ana Paula Rodrigues. Da fundamentação jusfilosófica à prática dos direitos humanos da pessoa idosa. Dignidade Re-Vista, v.6, n.11, dez 2020.

Na primeira fase da modernidade, que marca o rompimento gradual com o medievo, com a emergência do humanismo renascentista, a figura divina aos poucos deixa de ser a fundamentação e a razão última de todas as coisas e abre espaço para o homem como centro o antropocentrismo. Nesse período, destacam-se não apenas as contribuições em termos de artes plásticas, literatura, política e direitos, mas também uma filosofia pensada para o ser humano e sua centralidade. Aqui, a principal referência em termos de construção do conceito de dignidade humana é certamente Giovanni Pico della Mirandola (1463-1494), que redigiu um discurso específico sobre o conceito de dignidade humana, no qual afirma que o homem deve ser considerado um ser digno pelo simples fato de ter a capacidade de realizar as mais belas obras que podem ser vistas (Pico Della Mirandola, 1990). No entanto, foi apenas na segunda fase da modernidade filosófica, marcada pelo fechamento do debate entre racionalistas e empiristas, que os conceitos de dignidade e direitos humanos se tornaram amplamente divulgados pela filosofia, especialmente por meio do pensamento kantiano.

O contexto histórico de Immanuel Kant (1724-1804) denuncia um instante de complexidades sociais, culturais e políticas, no qual se emergia o sentimento revolucionário francês (Ramos, 2014, p.51), cuja finalidade era derrubar permanentemente as bases do Antigo Regime e estruturar uma nova sociedade, governada não mais por reis absolutistas, cujos poderes eram conformados pela vontade de Deus, mas sim pela burguesia. Além disso, o instante histórico de vivência e escrita de Kant coincide diretamente com o aparecimento dos direitos humanos de primeira dimensão - direitos civis e políticos -, erguidos a partir dos esforços revolucionários na França. Com o pensamento de Kant, especialmente sobre a filosofia dos costumes que desenvolve no âmbito das obras Kritik der Praktischen Vernunft (1788) e Grundlegung zur Metaphysik der Sitten (1797), respectivamente, Crítica da Razão Prática e Fundamentação da Metafísica dos Costumes, as bases do conceito de dignidade humana se alargam para abarcar uma premissa universal à humanidade.

O pensamento de Kant é essencialmente jusnaturalista ${ }^{1}$, ou seja, acredita que a lei justa não é fruto do poder e das decisões estatais, mas sim de um elemento que existe para além do

\footnotetext{
${ }^{1} \mathrm{O}$ jusnaturalismo compreende uma corrente jusfilosófica que se organiza por meio de três leis fundamentais: a) na realidade prática, há princípios de moralidade e de justiça que são universalmente válidos e acessíveis à razão humana, de modo que o jusnaturalismo representa, simultaneamente, uma aproximação às perspectivas ontológica (existência de princípios considerados universais) e lógicoepistemológica (apenas a razão é capaz de acessar tais princípios); b) no jusnaturalismo, o direito é entendido como um sistema que não contradiz a lógica do direito natural, de modo que cabe ao mundo jurídico apenas prescrever ou proibir aquilo que é considerado bom ou ruim segundo a lex naturalis; c) no jusnaturalismo, os sistemas jurídicos são conformados pelos princípios da moralidade e da justiça, ou seja, cabe ao direito se identificar com tais princípios ou se abster de contradizê-los (Bobbio; Matteucci; Pasquino, 1998). Portanto, pode-se afirmar que o jusnaturalismo representa a "doutrina
} 
Estado (Bobbio; Matteucci; Pasquino, 1998). Em sua filosofia, tal elemento é a própria razão humana, de modo que, para ele, as leis jurídicas e éticas são formulações das leis da razão que são apriorísticas e, portanto, universais e necessárias, aplicáveis a todos os seres humanos -, de modo que todas as leis nascidas do Estado não necessariamente respeitarão o imperativo categórico, que, como uma construção filosófica tipicamente kantiana, representa uma máxima segundo a qual devemos agir de modo que nossa conduta se torne universal (Kant, 2007). No pensamento kantiano, é justamente desse imperativo que nasce outra fórmula sintetizadora da dignidade humana, pela qual, no reino dos fins, tudo possui preço ou dignidade e, “(...) quando uma coisa está acima de todo o preço e, portanto, não permite equivalente, então ela tem dignidade" (Kant, 2007, p.77).

Nesse viés, se a filosofia consolidou o corpus teórico para se pensar e conceituar direitos e dignidade humana em um primeiro momento, em outro foi responsável por afirmar tais categorias como construções histórico-culturais (Ramos, 2014, p.54), que se estruturaram de acordo com as diferentes visões e problemas da história. O (re)nascimento constante dos direitos humanos e da noção de dignidade, enquanto promessas da modernidade, é inerente ao próprio desenvolvimento das sociedades modernas, que tiveram como cerne a necessidade de romper com as bases autoritárias do direito divinamente concedido aos monarcas no período absolutista, além de promover uma profunda mudança no pensamento social e no modo de enfrentamento a determinadas questões sensíveis de cada tempo. Assim, enquanto produtos sociais, históricos e culturais, os direitos humanos surgem na modernidade como promessas irrealizadas em relação aos grupos vulneráveis - e, consequentemente, produtos formadores de uma ética cultural comum (Trindade, 2003, p.35).

Ao se conjecturar diferentes fases dos direitos humanos, que oscilam entre a produção de garantias de cunho civil e político ou social, econômico e cultural, a filosofia se mostra como o instrumento por excelência para fundamentar, segundo as leis da razão humana, o que se compreende por direitos humanos e, principalmente, por dignidade humana. $\mathrm{O}$ desenvolvimento dessa tipologia segundo as normas do pensamento filosófico são fundamentais para consolidar um sentido de respeito universal a tais garantias, uma vez que, segundo a própria máxima kantiana do imperativo categórico da humanidade, é preciso agir de modo a não lesar o outro e fazer com que nossa ação seja moralmente válida e tenha caráter

segundo a qual existe e pode ser conhecido um 'direito natural' (ius naturale), ou seja, um sistema de normas de conduta intersubjetiva diverso do sistema constituído pelas normas fixadas pelo Estado (direito positivo)" (Bobbio; Matteucci; Pasquino, 1998, p.655). 
SPINIELI, André Luiz Pereira; NALIN, Ana Paula Rodrigues. Da fundamentação jusfilosófica à prática dos direitos humanos da pessoa idosa. Dignidade Re-Vista, v.6, n.11, dez 2020.

universal. Nesse sentido, deve-se pensar os direitos das populações vulneráveis sob o crivo de uma ética universal e do reconhecimento desses indivíduos como sujeitos de direito.

\section{Por um sentido crítico e não estático de dignidade e direitos humanos}

A construção social, histórica e cultural dos direitos humanos ao longo da modernidade, especialmente por meio das forças revolucionárias francesas e do pensamento iluminista, que serviram de base para inverter a lógica de dominação política exercida desde os instantes do Antigo Regime (Ramos, 2014, p.53), demonstrou que essas garantias estavam socialmente inseridas em um sentido setorial e exclusivo para determinadas classes. Essa crítica é desenvolvida por Marx (2010, p.47-48), ao observar a existência de uma separação abissal entre os sujeitos que eram considerados cidadãos (citoyen) e os outros, nomeados puramente de homens (les hommes). A crítica marxiana aos resultados jurídico-humanitários da Revolução Francesa ainda se faz factível na atualidade, uma vez que, embora os direitos humanos estejam posicionados nos ordenamentos jurídicos nacional e internacional em posição de destaque, há dificuldades em se materializar tais garantias.

De acordo com Sánchez Rubio (2015), essa dificuldade é mais simplesmente observada em espaços sociais nos quais as diferentes formas de desigualdade e vulnerabilidade de direitos se fazem presentes, de modo que se materializa, ao invés de direitos humanos, uma bipolaridade no agir humano frente à realização prática dessas garantias. Significa dizer que, em alguns casos, se torna válido respeitá-los e reconhecê-los como categorias aplicáveis a todos os sujeitos, mas, em outros, há uma decisão organizada no sentido de não cumprir os imperativos dos direitos humanos, inclusive ignorando os níveis de afetação negativa da não implementação dessas garantias para sujeitos vulneráveis (Rubio, 2015). Em realidade, tal como o conceito de dignidade humana, os direitos humanos não podem ser considerados produtos finalizados como propugnava o jusnaturalismo kantiano, que os entendia como frutos da razão humana -, senão como categorias que se moldam às diferentes concepções de cidadania que atravessam a história ocidental, como padrões que não necessariamente se encaixam naquilo que é montado por um "alfaiate" (Rubio, 2014, p.90).

A partir do prisma da teoria crítica aplicada aos direitos humanos, surge a necessidade de localizá-los na história como produtos culturais, surgidos desde as lutas levadas a cabo por grupos marginalizados em prol do reconhecimento formal e da realização material de seus direitos. Enxergar os direitos humanos e o conceito de dignidade como elementos que não se 
moldam às reivindicações de grupos vulneráveis significa reconhecer que, em face dessas populações - que também são vítimas de assimetrias históricas e culturais -, vige um estado em que "a experiência da 'exclusão' é um ponto de partida (e não de chegada) cotidiano (...)" (Dussel, 1995, p.60). Essa perspectiva demonstra que a epistemologia dos direitos humanos e da dignidade humana conforme foi concebida durante os atos revolucionários franceses, de cunho liberal, é essencialmente insuficiente para garantir a materialização dos direitos das populações vulneráveis.

\section{Como afirma Paulo Roberto Ramos, na contemporaneidade}

(...) os direitos humanos redimensionaram-se, deixando de ter apenas a perspectiva segundo a qual a sua garantia se daria apenas com a limitação do poder arbitrário do Estado por estar vedado a este efetuar qualquer interferência na vida privada. Passaram a requerer para a sua efetiva implementação a interferência do Estado na vida dos cidadãos, sem, contudo, atingir as suas liberdades individuais, conquistadas anteriormente. Todavia, a linha de equilíbrio entre a não interferência, por desnecessária, e a interferência, por imprescindível, parece encontrar-se no nível da consciência de cada ser humano de que não nasceu para ser privado de qualquer tipo de liberdade, fato que somente se transformará num valor efetivo quando houve a intensa participação dos homens, de todos os homens, no processo de decisão política dos seus respectivos países, que devem ter como metas o desenvolvimento e a democracia e desse processo os velhos não podem estar excluídos. (Ramos, 2014, p.62, grifos no original)

Por definição, grupos vulneráveis estão sujeitos à menor provisão de direitos humanos na prática, o que reverbera diretamente em sua esfera existencial e, principalmente, no sentido de sua dignidade humana. De crianças e adolescentes a pessoas idosas que não acessam seus direitos humanos, o denominador comum de tais exclusões, que se materializam prioritariamente em sociedades periféricas (Machado, 2017, p.22-23), está fixado na dificuldade de implementar tais garantias. A partir dessa problemática que se identifica em face dos direitos humanos na contemporaneidade, desde uma visão crítica, é que surge a necessidade de um movimento de (re)invenção dessas garantias, para que tenham como ponto de partida novas concepções jurídicas que assimilem os direitos e a dignidade humana como resultados de lutas e processos sociais, históricos, econômicos, políticos e culturais (Flores, 2005, 2009), que estejam alinhados aos interesses e reivindicações de populações vulneráveis, minorias, vítimas e ninguneados ${ }^{2}$.

\footnotetext{
2 O termo ninguneado é trabalhado por Octávio Paz, que empregava a palavra em um contexto literário de retrato de representações sociais simbólicas sobre a parcela da população que se encontrava à margem da ideologia hegemônica e, concomitantemente, invisível aos demais indivíduos desse corpo social, para se referir às pessoas cuja existência é diariamente e socialmente apagada.
} 
Na verdade, os direitos humanos e o conceito de dignidade humana se tornaram estáticos diante do império da lei e do encastelamento das garantias no âmbito puramente legislativo. Como afirma Sánchez Rubio (2015), não há dúvidas de que os direitos humanos são categorias fundamentais para toda e qualquer sociedade. No entanto, contemporaneamente, estão sujeitos a efeitos de encantamento que leva a sociedade a tomar atitudes que não condizem com a efetivação material dessas garantias, tornando-as elementos restritos ao sentido legal e que são de difícil cumprimento no cotidiano e na prática (Rubio, 2015, p.100-101). Nesse sentido, verifica-se que a perspectiva crítica dos direitos humanos, que nasce como negação do direito positivista, denuncia os abismos sociais, políticos e culturais existentes entre teoria e prática de direitos, tal como a transformação promovida nesse campo, que levou os direitos humanos de promessas parcialmente factíveis e setoriais para puras abstrações legais, expondo a existência de um paradoxo.

A condição paradoxal dos direitos humanos na contemporaneidade se acirrou a partir do instante em que olhares mais atentos foram lançados sobre os segmentos sociais considerados vulneráveis (Ramos, 2014, p.64). Isso se deve ao fato de se tratar de populações que estão cotidianamente sujeitas a posições sociais de inferioridade e afastamento crônico em relação aos seus direitos humanos, fazendo com que haja um claro aprofundamento das desigualdades e assimetrias sociais (Machado, 2017, p.22-23). Para isso, ao se discutir a proteção de grupos considerados vulneráveis em face dos direitos humanos, é preciso ter claro que, "sem desenvolvimento não serão assegurados os direitos civis, políticos, sociais, econômicos e culturais" (Ramos, 2014, p.65), impondo que os direitos humanos deixem de ser meros recursos retóricos e passem à esfera da materialidade.

Em relação aos direitos da pessoa idosa, à imagem e semelhança do que se opera com os demais direitos atinentes às populações vulneráveis, há grande descrédito no que tange à materialização (Ramos, 2014). A dificuldade de prover espaços acessíveis e acesso das pessoas idosas aos seus direitos humanos, especialmente de segunda dimensão, exige diretamente o dispêndio de recursos econômicos por parte do Estado, o que termina fragilizado em espaços de baixo desenvolvimento econômico (Machado, 2017, p.22-23; Sarlet, 2007, p.305), caminhando em conjunto com a dificuldade de oferecer um conceito inclusivo de pessoa idosa, que esteja além da perspectiva exclusivamente cronológica, além de noções exatas de velhice e envelhecimento segundo o direito e o paradigma da dignidade humana. Portanto, a teoria crítica aplicada aos direitos humanos se torna fundamental para oferecer um olhar às populações 
SPINIELI, André Luiz Pereira; NALIN, Ana Paula Rodrigues. Da fundamentação jusfilosófica à prática dos direitos humanos da pessoa idosa. Dignidade Re-Vista, v.6, n.11, dez 2020.

vulneráveis e à materialização de seus direitos que estejam de acordo com as perspectivas contemporâneas, das sociedades inclusivas e não discriminatórias.

\section{Envelhecimento saudável e velhice como categorias inerentes aos direitos humanos}

A incorporação dos direitos humanos no plano interno dos Estados a partir do reconhecimento dessas garantias por meio de tratados e convenções internacionais é um fator que foi incrementado na atualidade, através da globalização e de seus efeitos. Nesse sentido, a busca pela garantia internacional e intraestatal dos direitos humanos da população idosa constitui um elemento de centralidade, ao lado da busca pela efetivação formal de direitos de outros grupos considerados vulneráveis. No cenário contemporâneo, a população idosa compreende um contingente de aproximadamente $12 \%$ de toda a população mundial, havendo estimativas de que esse número seja duplicado até o ano de 2051 ou mesmo triplicado até 2100 (Suzman et al., 2015). A contemporaneidade trouxe, além da inefetividade crônica dos direitos humanos dessa população, novas ondas de práticas discriminatórias e exclusão social de grupos vulneráveis. Tais problemáticas vêm sendo ampliadas com o crescente número de pessoas idosas no mundo, trazendo à tona a necessidade de colocar em discussão os conceitos de velhice e envelhecimento saudável como categorias inerentes à epistemologia dos direitos humanos.

Diante das crescentes taxas de pessoas idosas no mundo e em virtude da dificuldade de materialização de direitos dessa população, o tema se tornou pauta na agenda internacional dos direitos humanos, permitindo uma primeira aproximação dos conceitos de velhice e envelhecimento saudável da perspectiva de inerência a esses direitos e à noção de dignidade humana. O esforço inicial foi concretizado no Plano de Ação Internacional, organizado na II Conferência Mundial do Envelhecimento, promovida pela Organização das Nações Unidas (ONU) no ano de 2002, em Madri. Apesar dos esforços internacionais em concretizar uma agenda apropriada ao reconhecimento, proteção e promoção dos direitos da pessoa idosa, a persistência de uma mentalidade e de uma cultura jurídico-social positivista, que impede a transformação fática dessas garantias, trouxe problemas ao desenvolvimento da velhice e do envelhecimento saudável enquanto elementos existenciais e presentes em todas as pessoas (Ramos, 2014). Em virtude disso, partiu-se da necessidade de articular alternativas por meio de políticas públicas, sobretudo aquelas que enfocam a questão da saúde (Tavares et al., 2017). 
O processo de envelhecimento implica a necessidade de desenvolvimento do senso de alteridade da sociedade, como uma das formas de proteção da pessoa idosa. Isso porque o avançar da idade é parcela fundamental do ser humano, como uma característica tipicamente ontológica, que pertence ao sentido de ser pessoa humana. Assim, o envelhecimento carrega consigo diferentes transformações na constituição social, cultural e física do indivíduo, que podem ser visualizadas em quatro categorias: a) biológicas, que compreendem as modificações morfológicas e fisiológicas, como o aparecimento de rugas e as mudanças no organismo, respectivamente; b) físicas, que são visualizadas, por exemplo, na aquisição da mobilidade reduzida; c) psicológicas, que contempla os problemas de adaptabilidade da pessoa idosa em face das novas situações de seu cotidiano, especialmente quanto às suas limitações; e d) sociais, associadas às problemáticas de discriminação em razão da condição de sua idade (Santos, 2010, p.1036).

Além das dificuldades atinentes ao reconhecimento da condição de pessoa idosa como um elemento inerente à constituição humana, ainda pesam desafios em relação aos conceitos de envelhecimento saudável e velhice. Atualmente, a Organização Mundial da Saúde (OMS) tem reformulado conceitos pertinentes à tutela dos direitos da pessoa idosa, especialmente a noção de envelhecimento saudável, que passou a ser considerada segundo as vertentes da capacidade e da habilidade da pessoa idosa, tornando-se um conceito que se estabelece enquanto um "processo de desenvolvimento e manutenção da capacidade funcional que permite o bem-estar na idade avançada" (World Health Organization, 2015, p.28; Beard, 2016, p.2152). Desse modo, o conceito de envelhecimento saudável se tornou indissociável do reconhecimento e efetivação de outros direitos humanos, como as formas de acessibilidade arquitetônica, comunicacionais e atitudinal em face da pessoa idosa, uma vez que tal noção carrega consigo as dimensões da capacidade funcional da pessoa e de características intrínsecas ao ambiente.

O mesmo fenômeno teve espaço com o conceito de envelhecimento, que terminou enfocado pela legislação nacional e internacional como uma questão puramente etária, o que motivou a escolha do princípio cronológico como mecanismo para a determinação de quem se inclui ou não na categoria da pessoa idosa. Na verdade, uma concepção crítica de envelhecimento associada também à perspectiva crítica dos direitos humanos, deve estar além do engessamento provocado pela lei, uma vez que esse encarceramento provocou o entendimento social da velhice como uma questão que faz com que a população idosa seja enxergada como grupo cuja produtividade - no sentido capitalista - é fraca e insuficiente para que sejam considerados cidadãos merecedores de direitos humanos. No âmbito da vertente 
crítica, a velhice passaria a ser compreendida como uma construção social e cultural, que classifica seres humanos de acordo com um critério que ultrapassa o sentido etário, mas que também visualiza a capacidade cognoscitiva, de acesso aos espaços públicos, de exercício de outros direitos e mesmo de rompimento com a marginalidade social daqueles que hoje são socialmente considerados idosos.

Nesse viés, afirma Paulo Roberto Ramos:

A velhice é o direito que deixa mais claro serem todos os direitos humanos indissociáveis, pois depende, para a sua afirmação, não somente da garantia do direito à vida, mas da garantia do direito à vida com dignidade, só possível em sociedades que asseguram o desenvolvimento e o ambiente democrático. A afirmação da velhice como direito humano fundamental é capaz de desenvolver a ideia inafastável de que a todos os homens devem ser asseguradas condições mínimas de existência para que consigam gozar de todas as fases da vida com plenitude, sem qualquer interrupção por falta de liberdade, notadamente material. Viver com dignidade é estar livre das privações e esta vida, por certo, as sociedades precisam garantir a todos os seres humanos. (Ramos, 2014, p. 72)

A composição das sociedades por um contingente cada vez mais crescente de pessoas idosas implica a promoção de "mudanças também na forma de pensar, de sentir e de agir dos seres humanos que passam por esta etapa do processo de viver" (Santos, 2010, p.1036). Desse modo, pode-se considerar que está em contrariedade à perspectiva contemporânea dos direitos humanos - metafisicamente considerado, e não segundo as bases estatais -, o fato do direito se contentar com a mera retirada da população idosa do núcleo dos estigmas da invalidez, da improdutividade capitalista e da condição de pessoa em decadência. Na verdade, é necessária uma perspectiva não estática, que tenha como finalidade última retirar direitos do papel e aplicálos na realidade material, tomando como cerne exatamente as populações vulneráveis, dentre as quais destacamos os idosos, que, não nasceram assim, mas também foram crianças, adolescentes e adultos, marcados por outras espécies de vulnerabilidade ao longo da vida (Ramos, 2014).

Tomar os conceitos de envelhecimento saudável e velhice como elementos intrínsecos à proposta contemporânea dos direitos humanos significa entender que o processo de envelhecimento é "decorrência de condições sociais favoráveis de existência ou dos avanços da tecnologia médica ou ainda de ambos" (Ramos, 2014, p.74). A fase da terceira idade constitui expressão da dignidade humana porque é, ao mesmo tempo, o aspecto de uma vida que usufruiu das garantias mínimas do mínimo existencial e de alguém que possui experiências e lembranças acumuladas, que devem ser respeitadas como parcelas de um patrimônio comum da 
SPINIELI, André Luiz Pereira; NALIN, Ana Paula Rodrigues. Da fundamentação jusfilosófica à prática dos direitos humanos da pessoa idosa. Dignidade Re-Vista, v.6, n.11, dez 2020.

humanidade. Assim, a inserção do envelhecimento saudável e da velhice no núcleo dos direitos e da dignidade humana faz com que haja o reconhecimento social da pessoa idosa com o sentido de tolerância ao diferente, evitando que se construa uma sociedade de anti-idosos (Lafer, 2005).

\section{Considerações finais}

Sob o viés jusfilosófico, a conceituação de dignidade humana se posiciona em estado de suma importância para uma compreensão acerca do desenvolvimento dos direitos humanos, apesar de sua insuficiência para garantir a efetivação dessas garantias na vida material. A materialização dos direitos humanos está restrita a grupos hegemônicos, emergindo a necessidade uma cultura de direitos que reivindique sua colocação em prática, tendo como perspectiva um viés que tenha por finalidade reconhecer os sentidos da inclusão e não discriminação das populações vulneráveis. A população idosa está em franco crescimento no mundo e representa um grupo que se encontra sob o jugo das violações de seus direitos, especialmente em relação ao não reconhecimento da velhice e do envelhecimento saudável como questões inerentes aos direitos humanos. Uma vez que o próprio conceito de envelhecimento saudável está diretamente associado à materialização de direitos humanos ao longo da vida, conclui-se pela necessidade de extrapolar a atual cultura referente a esses direitos para efetivar uma realidade que esteja para além do encastelamento legal. 


\section{Referências bibliográficas}

BEARD, John R. The world report on ageing and health: a policy framework for healthy ageing. Lancet, v. 387, n.10, p.2145-2154, 2016.

BOBBIO, Norberto; MATEUCCI, Nicola; PASQUINO, Gianfranco. Dicionário de política. 11.ed. Brasília: Editora da Universidade de Brasília, 1998.

CARMO, Michelly Eustáquia do; GUIZARDI, Francini Lube. O conceito de vulnerabilidade e seus sentidos para as políticas públicas de saúde e assistência social. Cadernos de Saúde Pública, v.34, n.3, p.1-14, 2018.

DUSSEL, Enrique. Filosofia da libertação: crítica à ideologia da exclusão. São Paulo: Paulus, 1995.

FLORES, Joaquín Herrera. A reinvenção dos direitos humanos. Trad. Carlos Roberto Diogo Garcia; Antônio Henrique Graciano Suxberger; Jefferson Aparecido Dias. Florianópolis: Fundação Boiteux, 2009.

FLORES, Joaquín Herrera. Los derechos humanos como productos culturales: crítica del humanismo abstracto. Madrid: Catarata, 2005.

JAEGER, Werner. Paideia: a formação do homem grego. Trad. Artur M. Parreira. 3.ed. São Paulo: Martins Fontes, 1994.

KANT, Immanuel. Fundamentação da metafísica dos costumes. Trad. Paulo Quintela. Lisboa: Edições 70, 2007.

MACHADO, Antônio Alberto. Elementos de teoria dos direitos fundamentais. Franca: Cultura Acadêmica, 2017.

MARX, Karl. Sobre a questão judaica. São Paulo: Boitempo, 2010.

PICO DELLA MIRANDOLA, Giovanni. Über die Würde des Menschen. Frankfurt: Meiner, 1990.

RAMOS, Paulo Roberto Barbosa. Curso de direito do idoso. São Paulo: Saraiva, 2014.

RUBIO, David Sánchez. Encantos e desencantos dos direitos humanos: de emancipações, libertações e dominações. Porto Alegre: Livraria do Advogado, 2014.

SALLES, Sérgio de Souza. Os sentidos de dignidade em Tomás de Aquino. XXIV Congresso Nacional do CONPEDI: Filosofia do Direito I. Belo Horizonte: CONPEDI, 2015.

SANTOS, Silvana Sidney Costa. Concepções teórico-filosóficas sobre envelhecimento, velhice, idoso e enfermagem gerontogeriátrica. Revista Brasileira de Enfermagem, Brasília, v.63, n.3, p.1035-1039, nov/dez 2010. 
SARLET, Ingo Wolfgang. A eficácia dos direitos fundamentais. 8.ed. Porto Alegre: Livraria do Advogado, 2007.

SARMENTO, Daniel. Dignidade da pessoa humana: conteúdo, trajetórias e metodologia. Belo Horizonte: Fórum, 2016.

SUZMAN, Richard et al. Health in an ageing world: what do we know? Lancet, v.7, n.385, p.484-486, 2015.

TAVARES, Renata Evangelista et al. Envelhecimento saudável na perspectiva de idosos: uma revisão integrativa. Revista Brasileira de Geriatria e Gerontologia, v.20, n.6, p.889-900, 2017.

TRINDADE, Antônio Augusto Cançado. Tratado de direito internacional dos direitos humanos. v.1. Porto Alegre: Sérgio Antônio Fabris Editora, 2003.

WORLD HEALTH ORGANIZATION. World report on ageing and health. Geneva: World Health Organization, 2015. 